Windsor, H.M. \& Shanahan, M.X. (1967) Emergency valve replacement in bacterial endocarditis. Thorax, 22, 25.

Wise, J.R., Cleland, W.P., Hallidie-Smith, K.A., Bentall, H.H., Goodwin, J.F. \& OAKLeY, C.M. (1971) Urgent aortic valve replacement for acute aortic regurgitation due to infective endocarditis. Lancet, ii, 115.
Yacoub, M., Pennacchio, L., Ross, D. \& McDonald, L. (1972) Replacement of mitral valve in active infective endocarditis. British Heart Journal, 34, 758.

Yeh, T.J., Hall, D.P. \& Ellison, R.G. (1964) Surgical treatment of aortic valve perforation due to bacterial endocarditis. American Surgeon, 30, 766.

\title{
Primary acquired hypogammaglobulinaemia and auto-immune thyroiditis
}

\author{
Angela M. Hilton \\ M.B., Ch.B., M.R.C.P.(U.K.) \\ University Hospital of South Manchester
}

\author{
L. DOYLE \\ M.B., F.R.C.P.(I) \\ Baguley Hospital, Manchester
}

\begin{abstract}
Summary
A patient with primary acquired hypogammaglobulinaemia and auto-immune thyroiditis is presented, an association which has not been described previously. The role of disturbances of cell-mediated immunity in the pathogenesis of the thyroid lesion is discussed.
\end{abstract}

PRIMARY acquired hypogammaglobulinaemia, characterized by frequent bacterial infections (particularly of the sinuses and respiratory tract), a very low serum level of $\gamma$ globulin and failure to produce antibody in response to antigenic stimulation has been associated with a variety of other disorders. These include diseases of the reticulo-endothelial system such as lymphosarcoma, Hodgkin's disease, leukaemia and multiple myeloma (Douglas, Goldberg and Fudenberg, 1970; Fudenberg, 1971) and auto-immune disorders including acquired haemolytic anaemia, rheumatoid arthritis (Fudenberg, 1971) and pernicious anaemia (Lee et al., 1964; Conn et al., 1968; Twomey et al., 1969).

An association between primary acquired hypogammaglobulinaemia and auto-immune thyroiditis has not been recorded previously and therefore the following case report is presented.

\section{Case report}

A 44-year-old man first presented in 1963 with a 10-year history of recurrent, frequent, febrile respiratory tract infections. Clinical examination and

Correspondence: Dr A. M. Hilton, c/o University Hospital of South Manchester, Department of Medicine, Teaching Unit 7, Withington Hospital, Nell Lane, Manchester M208LR. his chest X-ray suggested the presence of bilateral bronchiectasis. At that time he was found to have hypogammaglobulinaemia with a serum $\gamma$ globulin level of $10 \mathrm{mg} / 100 \mathrm{ml}$. He has received weekly injections of $\gamma$ globulin (supplied by the MRC) and had fewer and less severe chest infections since this diagnosis was made.

In January 1969, he was found to have the clinical features of myxoedema. For the preceding 6 months he had noticed increasing loss of energy, decreased tolerance of cold, dry skin, constipation and marked loss of hair and eyebrows. There was no family history of auto-immune disease or hypogammaglobulinaemia. Examination revealed marked alopecia, complete loss of eyebrows, dry skin, pale, puffy face, deep voice, mental slowing, a bradycardia and delayed supinator and ankle reflexes. It is of interest that the alopecia became total and has persisted ever since.

Investigations confirmed the clinical diagnosis of hypothyroidism with a PBI $0.5 \mu \mathrm{g} / 100 \mathrm{ml}$ and $\mathrm{I}^{131}$ uptake $2 \%$ at $71 \mathrm{hr}$ (normal $10-20 \%$ ). Other investigations including thyroid auto-antibodies, SCAT, ANF and Coombs test were all negative.

At the time of the original investigations of his hypogammaglobulinaemia (1963), it was decided to carry out a lymph node biopsy from the right side of the neck. Fortuitously, a small piece of accessory thyroid tissue was removed. Histological examination of this revealed pathological features consistent with a diagnosis of Hashimoto's or auto-immune thyroiditis. There was extensive infiltration of thyroid tissue by lymphocytes, but no plasma cells, and a small amount of fibrosis. 


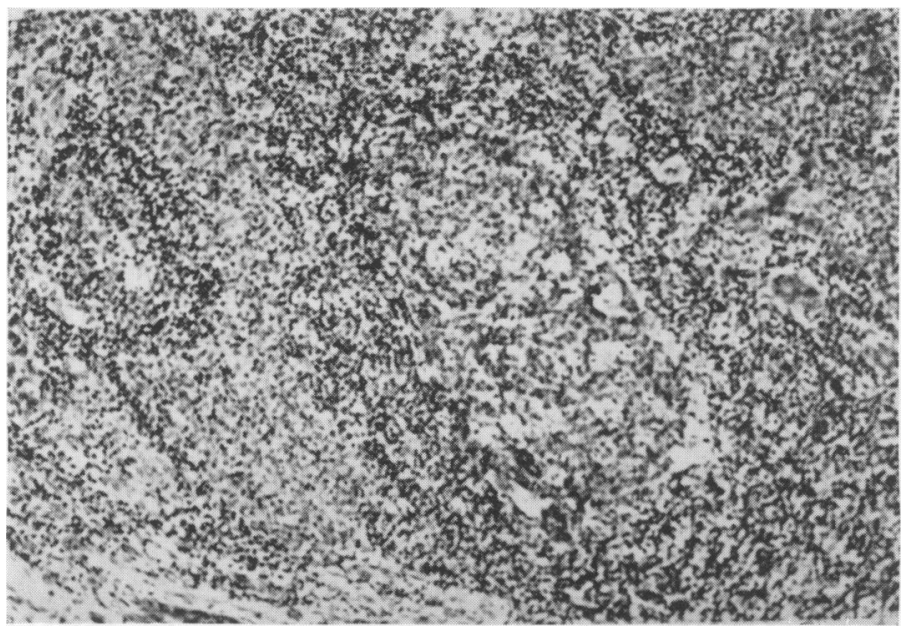

Fig. 1. Thyroid biopsy $(\times 100)$.

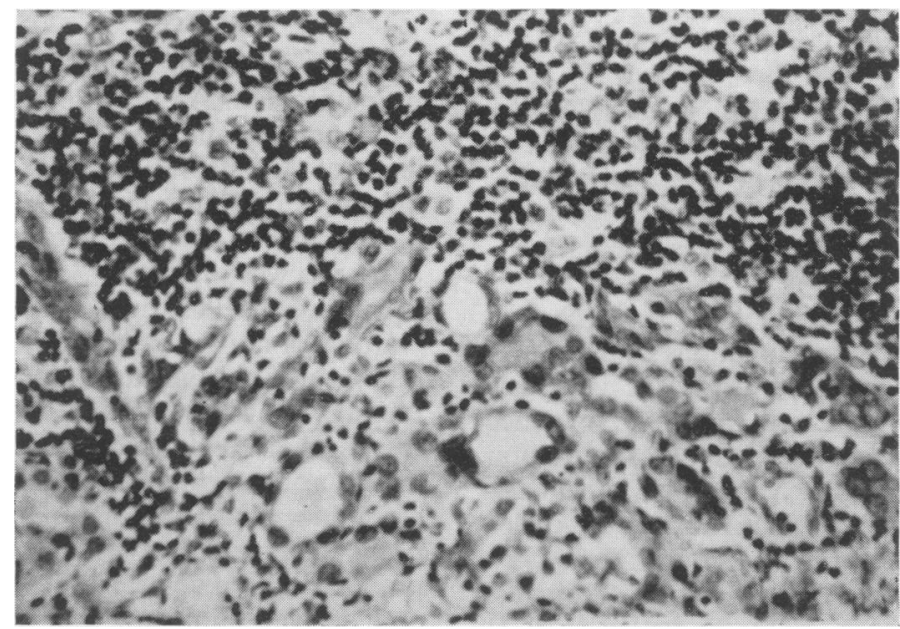

FIG. 2. Thyroid biopsy $(\times 250)$. Extensive infiltration of thyroid tissue with chronic inflammatory cells.

Investigation of the patient's cell-mediated immunity was confined to delayed hypersensitivity responses, initially to $1: 10,000$ and $1: 1000$ tuberculin and Candida albicans $0.05 \mathrm{ml}$ intradermally. These antigens failed to induce any reaction. Skin testing was then performed with 2,4dinitrochloro-benzene (DNCB) 2 weeks after initial sensitization. A characteristic delayed hypersensitivity reaction developed 5 days later. (Normal subjects show this response after 2 days.) Since commencing treatment with thyroxine he has remained in good health except for a recent admission be- N cause of a respiratory tract infection.

\section{Discussion}

Hashimoto's thyroiditis has been described in association with several other auto-immune disorders, including acquired haemolytic anaemia, idiopathic Addison's disease, pernicious anaemia and collagen diseases (Roitt and Doniach, 1960; Irvine et al., 1962; Schiller, Snyder and Vallotton, 1967). As primary acquired hypogammaglobulinaemia is 
also associated with these conditions, it is perhaps surprising that its association with auto-immune thyroiditis has not been described more frequently. One of a group of patients with gastric carcinoma and hypogammaglobulinaemia developed myxoedema but thyroid histology was not mentioned (Hermans and Huizenga, 1972). This patient may have had auto-immune thyroiditis.

The high incidence of auto-immune diseases in patients unable to produce antibodies provided convincing evidence that such antibodies were not essential for their pathogenesis (Twomey et al., 1969). The absence of thyroid autoantibodies in this patient would lend support to the conclusion that these antibodies are not essential for the pathogenesis of auto-immune thyroiditis, and that, in subjects capable of producing them, the formation of autoantibodies must be a phenomenon secondary to primary tissue damage.

Currently, much interest centres on the role of disturbances of cell-mediated immunity as a predisposing factor to the development of autoimmune diseases. Studies of cellular hypersensitivity in patients with Hashimoto's thyroiditis have suggested impairment of cell-mediated immunity in a high proportion of them (Søberg and Halberg, 1968). Other investigators have also demonstrated abnormalities of delayed hypersensitivity responses in patients with idiopathic acquired hypogammaglobulinaemia (Douglas et al., 1970). More recently, investigations of cellular responses in patients with pernicious anaemia and hypogammaglobulinaemia revealed further evidence of abnormal cell mediated immunity (Gelfand et al., 1972).

Our investigation of cell-mediated immunity in this patient was limited to delayed hypersensitivity skin testing but this suggested some impairment of cell-mediated immunity.

Thus, some patients with primary acquired hypogammaglobulinaemia appear to have impairment of both humoral and cell-mediated immunity. It is well established that their low levels of immunoglobulins predispose to recurrent bacterial infections and it may be reasonable to postulate that, similarly, abnormalities of cell-mediated immunity predispose to the development of autoimmune disorders in these patients.

\section{Acknowledgment}

We wish to thank Dr K. V. Lodge, Consultant Pathologist, Wythenshawe Hospital, Manchester, for the thyroid histology report.

\section{References}

Conn, H.O., Binder, H. \& Burns, B. (1968) Pernicious anaemia and immunologic deficiency. Annals of Internal Medicine, 68, 603.

Douglas, S.D., GoldberG, L.S. \& FudenberG, H.H. (1970) Clinical, serologic and leucocyte function studies on patients with idiopathic acquired agammaglobulinaemia and their families. American Journal of Medicine, 48, 48.

FUDENBERG, H.H. (1971) Genetically determined immune deficiency as the predisposing cause of 'autoimmunity' and lymphoid neoplasia. American Journal of Medicine, 51, 295.

Gelfand, E.W., Berkel, A.I., Godwin, H.A., Rocklin, R.E., DAvid, J.R. \& Rosen, F.S. (1972) Pernicious anaemia, hypogammaglobulinaemia and altered lymphocyte reactivity-a family study. Clinical and Experimental Immunology, 11, 187.

Hermans, P.E. \& Huizenga, K.A. (1972) Association of gastric carcinoma with idiopathic late-onset immunoglobulin deficiency. Annals of Internal Medicine, 76, 605.

Irvine, W.J., Davies, S.H., Delamore, I.W. \& Williams, A.W. (1962) Immunological relationship between pernicious anaemia and thyroid disease. British Medical Journal, 2, 454.

Lee, F.I., Jenkins, G.C., Hughes, D.T.D. \& Kazantzis, G. (1964) Pernicious anaemia, myxoedema, and hypogammaglobulinaemia - a family study. British Medical Journal, 1, 598.

RoITT, I.M. \& DoniaCH, D. (1960) Thyroid autoimmunity. British Medical Bulletin, 16, 152.

SCHILleR, K.F.R., SNYder, L.M. \& Vallotton, M.B. (1967) Gastric, haematological, and immunological abnormalities in Hashimoto's thyroiditis. Gut, 8, 582 .

SoberG, M. \& HALberG, P. (1968) Cellular hypersensitivity in Hashimoto's thyroiditis. Acta medica Scandinavica, 183, 101.

TWOMEY, J.J., Jordan, P.H., Jarrold, T., Trubowitz, S., RITZ, N.D. \& CONN, H.O. (1969) The syndrome of immunoglobulin deficiency and pernicious anaemia-a study of ten cases. American Journal of Medicine, 47, 340. 